Cite this: NewJ.Chem., 2013, 37, 409

Received (in Montpellier, France) 20th August 2012, Accepted 18th October 2012

DOI: $10.1039 / c 2 n j 40745 k$

www.rsc.org/njc

\section{Synthesis, electronic properties and packing modes of conjugated systems based on 2,5-di(cyanovinyl)furan or thiophene and imino-perfluorophenyl moieties $\dagger \neq$}

\author{
Chady Moussallem, Magali Allain, Frédéric Gohier and Pierre Frère*
}

\begin{abstract}
The synthesis, the electronic properties and the solid state arrangements of conjugated systems associating pentafluorophenyl units linked via azomethine bonds to a central 2,5-di(cyanovinyl)thiophene or furan moieties have been investigated. The crystal structures of the two compounds are analyzed in terms of intermolecular interactions involving hydrogen and halogen bonding, $\pi-\pi$ stacking and donor-acceptor interactions. Both structures reveal similar $\pi$-stacking of the molecules with nevertheless a more compact packing mode for the furan derivative. Moreover this structure is stabilized by several F...F interactions between the columns of molecules. By contrast for the thiophene derivative, the structure requires the insertion of $\mathrm{CH}_{2} \mathrm{Cl}_{2}$ to be stabilized via $\mathrm{Cl} \ldots \mathrm{F}$ interactions.
\end{abstract}

\section{Introduction}

Organic semiconductors (OSCs) are a subject of considerable current interest motivated by the perspective of achieving large area, low-cost, lightweight and flexible (opto)electronic devices. ${ }^{1-3}$ Many organic semiconductors used as active materials in organic field effect transistors (OFETs) and photovoltaic cells derive from linearly $\pi$-conjugated systems such as oligoacenes or thiophene based oligomers. $^{4-6}$ Careful modifications on the oligothiophene backbone allow us to control the energy levels of the HOMO and LUMO frontier orbitals and thus to tune crucial electronic properties such as ionization potential, electron affinity, absorption and emission properties. ${ }^{7-9}$ Nevertheless the physical properties of the materials are also strongly dependent on the supramolecular architecture. Weak intermolecular interactions such as hydrogen bonding, halogen bonding, $\pi-\pi$ stacking and donor-acceptor interactions represent the main tools of crystal engineering in order to control the organization of the molecules in the materials. ${ }^{10,11}$ The cofacial $\pi$-stacking structures in substituted acenes or oligothiophenes are favorable for an improvement in the charge carrier mobility compared to the classical herringbone-type structure observed in

LUNAM Université, Université d'Angers, MOLTECH-Anjou CNRS UMR 6200, SCL Group, 2 Boulevard Lavoiser, 49045 Angers cedex, France.

E-mail: Pierre.frere@univ-angers.fr; Fax: +33 241735005; Tel: +33 241735063

$\dagger$ Dedicated to the memory of Dr Nuria Gallego-Planas.

† Electronic supplementary information (ESI) available: Cyclic voltammogram and UV-Vis absorption spectra of $\mathbf{1}$ and $2,{ }^{1} \mathrm{H},{ }^{13} \mathrm{C}$ and ${ }^{19} \mathrm{~F}$ NMR spectra of $\mathbf{1}$ and 2 , computational data of 1 and 2. CCDC 896899 and 896900. For ESI and crystallographic data in CIF or other electronic format see DOI: 10.1039/c2nj40745k unsubstituted derivatives. ${ }^{12,13}$ In the field of semiconductor materials presenting electron acceptor character, a trend consists of associating perfluoroarene and thiophene units in order to enhance the electron affinity of corresponding materials. ${ }^{14,15}$ Depending on the number of perfluorophenyl moieties and on their relative positions in the conjugated backbone of modified oligothiophenes, $\mathrm{n}$ or p-type semiconductors materials have been obtained. ${ }^{14,16,17}$ In addition to the electron-withdrawing effect of the fluorine atoms to stabilize both the HOMO and LUMO levels, perfluoroarene units often allow enhancement of the $\pi$-stacking in the solid state. ${ }^{18,19}$ The examination of several structures of hybrid thiophene-perfluorobenzene derivatives reveals that most of the longer compounds in which the perfluorophenyl rings participate in the conjugated systems present a substantially planar core. For these planar thiophene-perfluorophenyl systems, the supramolecular organization is promoted by perfluorobenzene-thiophene interactions. ${ }^{14,15,20,21}$ n-Type oligothiophene semiconductors have also been developed by grafting electron withdrawing cyano groups. ${ }^{22,23}$ Moreover it has been demonstrated that the introduction of the cyano groups via tri or dicyanovinyl units promoted the cofacial $\pi-\pi$ arrangement assisted by the hydrogen bonds between cyano groups and the neighboring arenes. ${ }^{13,24-26}$

Unlike numerous semiconducting materials based on thiophene units, conjugated systems including a furan moiety have been scantily developed. Recently, it has been demonstrated that organic field effect transistors were obtained from oligofurans or hybrid thiophene-furan oligomers. ${ }^{27,28}$ In donor-acceptor systems, furans have also been used as an alternative to thiophenes for dye-sensitized solar cells and for 

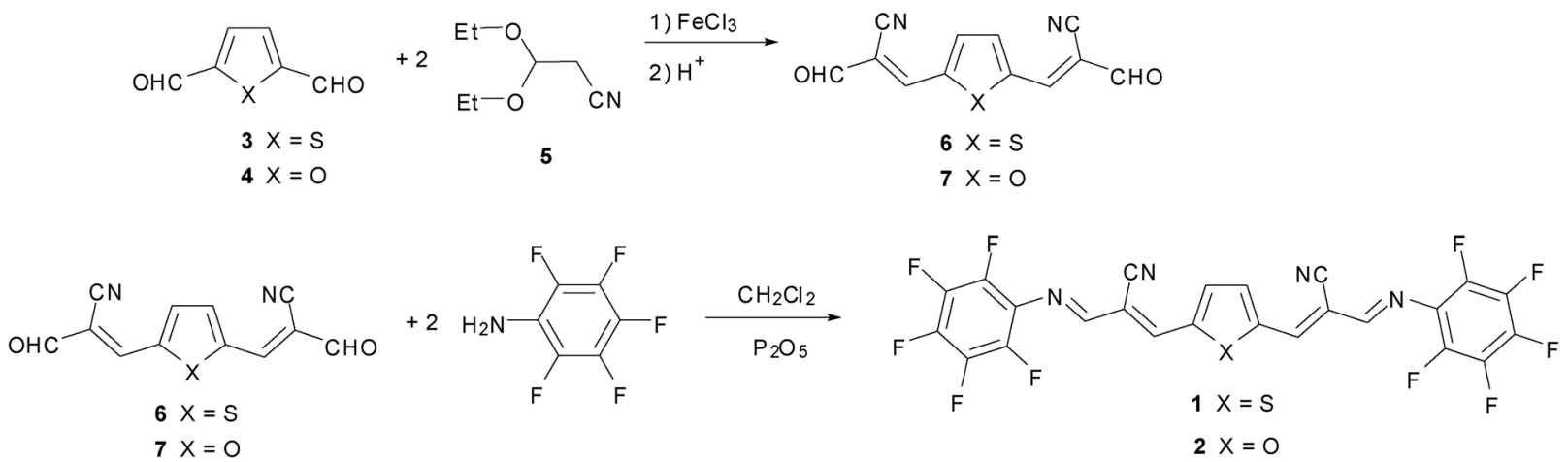

Scheme 1 Synthetic pathway of compounds 1 and 2 .

bulk heterojunction solar cells and have shown very similar properties than their homologue thiophene derivatives. ${ }^{29-31} \mathrm{We}$ reported earlier on structural features of conjugated materials associating furan and imino-perfluorophenyl units. We showed that the stacking modes were driven by a subtle balance of $\pi-\pi$ interactions and donor-acceptor interactions between the furan and perfluorophenyl moieties. ${ }^{32}$

In our effort of developing acceptor systems from hybrid heterocycle-perfluorophenyl structures and of studying the role of the perfluorophenyl rings in the stacking mode, we report here on the electronic properties and the structural features of the extended compounds 1 and 2 based on a central 2,5di(cyanovinyl)furan or thiophene unit linked to pentafluorophenyl groups via azomethine junctions (Scheme 1).

\section{Results and discussion}

The compounds 1 and 2 were synthesized in two steps from the 2,5-dicarbaldehyde thiophene 3 or furan 4 (Scheme 1). The first step corresponds to a condensation between 3,3-diethoxypropanenitrile 5 and dialdehydes 3 or 4 in the presence of $\mathrm{FeCl}_{3}$ as catalyst. $^{33}$ Bisformylacrylonitrile derivatives 6 and 7 were obtained in $28-30 \%$ yields after hydrolysis. Finally condensation reactions with pentafluoroaniline 8 were carried out at room temperature in dichloromethane and in the presence of a small amount of $\mathrm{P}_{2} \mathrm{O}_{5}$ to give the target molecules $\mathbf{1}$ and 2 in $30-35 \%$ yields.

The electronic properties of compounds 1 and 2 have been evaluated by theoretical calculations and analyzed by UV-Vis spectroscopy and by cyclic voltammetry (CV). The theoretical and experimental data are gathered in Table 1.

Table $1 \mathrm{HOMO}$ and LUMO energy levels, theoretical bandgap $\Delta E$, experimental absorption data and cyclic voltammetry data of compounds $\mathbf{1}$ and $\mathbf{2}$

\begin{tabular}{lllllll}
\hline Compounds & $\begin{array}{l}\mathrm{HOMO}^{a} \\
(\mathrm{eV})\end{array}$ & $\begin{array}{l}\mathrm{LUMO}^{a} \\
(\mathrm{eV})\end{array}$ & $\begin{array}{l}\Delta E_{\text {theo }}{ }^{a} \\
(\mathrm{eV})\end{array}$ & $\begin{array}{l}\lambda_{\max }{ }^{b} \\
(\mathrm{~nm})\end{array}$ & $\begin{array}{l}\Delta E_{\mathrm{opt}}{ }^{c} \\
(\mathrm{eV})\end{array}$ & $\begin{array}{l}E_{\text {red }}{ }^{2} \\
(\mathrm{~V})\end{array}$ \\
\hline $\mathbf{1}$ & -6.67 & -4.02 & 2.65 & 440 & 2.48 & -0.60 \\
$\mathbf{2}$ & -6.64 & -3.99 & 2.65 & 431 & 2.48 & -0.61
\end{tabular}

${ }^{a}$ B3LYP/6-31 G(d,p). ${ }^{b} 10^{-5} \mathrm{M}$ in $\mathrm{CH}_{2} \mathrm{Cl}_{2} \cdot{ }^{c}$ Optical bandgap calculated from the edge of the absorption band. ${ }^{d} 2 \times 10^{-5} \mathrm{M}$ in $0.1 \mathrm{M}$ $\mathrm{Bu}_{4} \mathrm{NPF}_{6}-\mathrm{CH}_{2} \mathrm{Cl}_{2}$, scan rate $100 \mathrm{mV} \mathrm{s}{ }^{-1}, \mathrm{~V}$ vs. SCE.

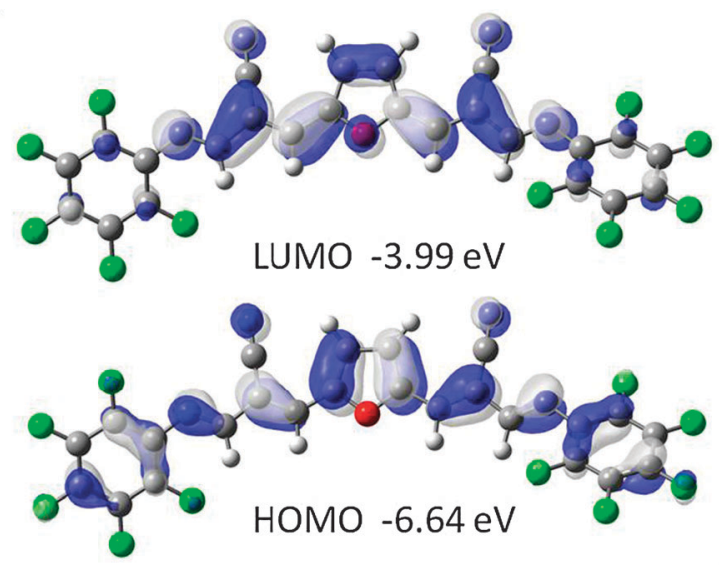

Fig. 1 Calculated HOMO and LUMO and energy levels for compound 2

Theoretical calculations were performed at the $a b$ initio density functional level with the Gaussian09 package. Becke's three parameter gradient-corrected functional (B3LYP) with a polarized 6-31G (d,p) was used for the geometrical optimization and for the HOMO and LUMO levels determination. The optimized structures of $\mathbf{1}$ and $\mathbf{2}$ present a planarity of the central conjugated systems with the two cyano groups in the plane defined by the heterocycle while the lateral perfluorophenyl units present rotational angles of $31^{\circ}$ with the central heterocycle. As shown in Fig. 1 the HOMO resides wholly on the conjugated backbones while the LUMO is only localized in the middle part excluding the pentafluorophenyl groups. The energy levels of the HOMO and LUMO of compounds 1 and 2 are very similar and are very stabilized with values of about -6.6 and $-4.0 \mathrm{eV}$ respectively giving a gap of $2.65 \mathrm{eV}$ for the two compounds. The nature of the central heteroatom has a limited influence on the electronic properties of the derivatives. On the other hand the acceptor character of the compounds is mainly due to the strong electron withdrawing cyano groups.

The electron acceptor character of the compounds $\mathbf{1}$ and $\mathbf{2}$ is confirmed by their electrochemical properties in $\mathrm{CH}_{2} \mathrm{Cl}_{2}$. The two compounds 1 and 2 present an irreversible reduction peak at $-0.6 \mathrm{~V} / \mathrm{SCE}$ (Fig. S1 in ESI $\ddagger$ ), which corresponds to the formation of a radical anion, but no oxidation peak has been observed. 
The UV-Vis absorption spectra of the two compounds in $\mathrm{CH}_{2} \mathrm{Cl}_{2}$ exhibit broad absorption bands with maxima at $440 \mathrm{~nm}$ for 1 and $438 \mathrm{~nm}$ for 2 (Fig. S2 in ESI $\ddagger$ ). The optical bandgaps calculated from the edge of the absorption bands at $2.48 \mathrm{eV}$ are independent of the central heteroatom thus confirming the theoretical calculations.

The strong difference between the two compounds is mainly observed in the stability of the crystals. Single crystals suitable for X-ray diffraction analysis are easily obtained for compound 2 by slow evaporation of dichloromethane-chlorobenzene or chlorobenzene solution. The orange crystals are stable at room temperature and can be handled under an air atmosphere. Single crystals of compound $\mathbf{1}$ are only obtained by slow evaporation of dichloromethane-chlorobenzene solution and the crystals are not stable in air at room temperature and they must be kept in the solvent. The X-ray diffraction analysis was performed in air at room temperature for compound 2 while the poor stability of the crystals of 1 required carrying out the diffraction analysis at $200 \mathrm{~K}$ under a nitrogen atmosphere. The two compounds crystallize in the monoclinic space group $C 2 / c$. The structures are defined from a half of molecule which lies on a two-fold axis. Compound 1 crystallizes with a dichloromethane molecule. The cell parameters are very close for the two crystals with nevertheless a longer value of $c=12.98 \AA^{3}$ for crystal 1 compared to $c^{\prime}=9.66 \AA^{3}$ for 2 that corresponds to the insertion of the solvent molecule. Fig. 2 and 3 display the molecular structures and the packing mode of crystals 1 and 2 respectively.

The two molecules adopt a $\mathrm{Z}$ configuration and a $\delta$-trans conformation (the cyano groups are oriented in the opposite direction pointing to the central heteroatom) for the acrylonitrile units and an $E$ configuration for the imine bonds. Although these optimized conformations give a substantial planarity of the central conjugated systems, a slight distortion of the molecules is observed in the two structures, which is more important for 2 than for $\mathbf{1}$. For compound 1, the maximum displacements for the atoms of the conjugated systems from the plane defined by the carbon atoms of the thiophene rings are $0.156 \AA$ and $0.131 \AA$, respectively, for the carbon atom and the nitrogen atom of the imine link. The cyano groups are slightly oriented above and below the plane with a displacement of the nitrogen atoms relative to the plane of $\pm 0.437 \AA$ A. The external

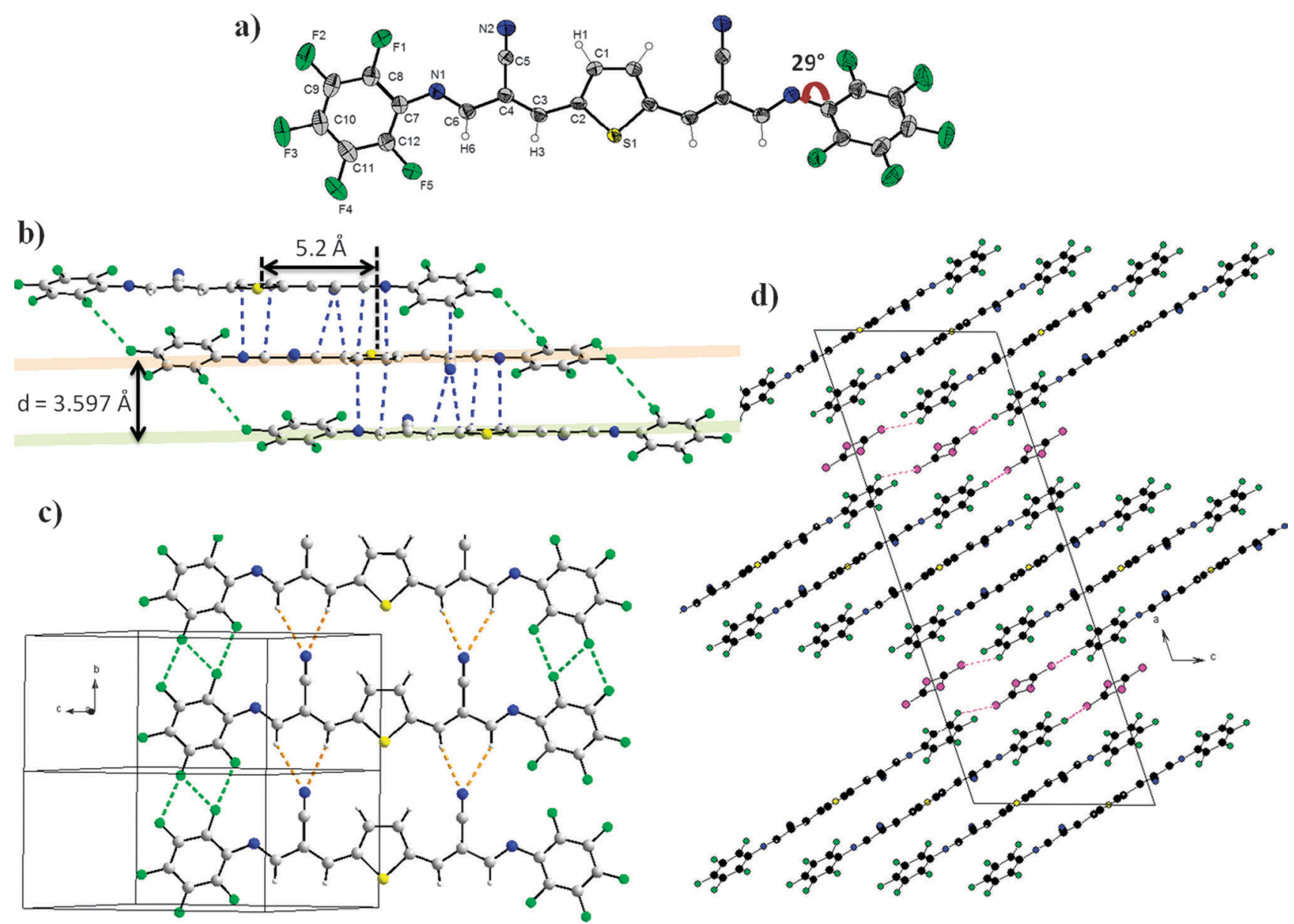

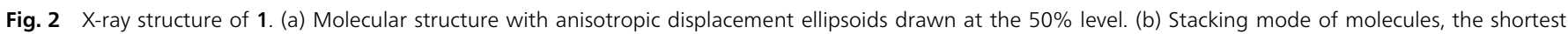

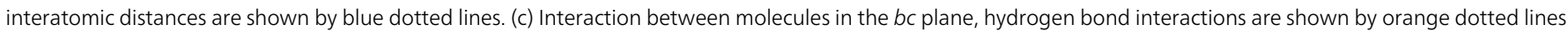

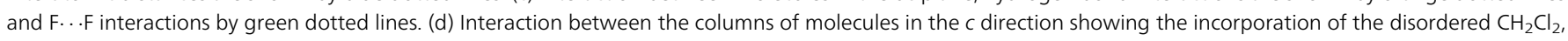
the $\mathrm{Cl} \ldots \mathrm{F}$ interactions are shown by purple dotted lines. 
pentafluorophenyl rings assume a torsional angle of $29.0^{\circ}$ with respect to the imine links.

For compound 2, the shift of the cyano groups above and below the plane defined by the carbon atoms of the furan rings with a displacement of the nitrogen atoms that reaches $\pm 0.799 \AA$ A. The pentafluorophenyl rings present a more important torsional angle of $41.7^{\circ}$ with respect to the imine links.

The molecules overlap by presenting a shift of the central heterocycles of $5.2 \AA$ for 1 and of $3.4 \AA$ for 2 . Thus the thiophene ring of molecule 1 superposes the imine links of two other molecules located above and below while for compound 2 the furan ring overlaps the cyano groups. The distances separating the planes defined by the heterocycles are slightly shorter for compound 2 with $d=3.533 \AA$ than for 1 with $d=3.597 \AA$. Such a stacking corresponds to $\pi-\pi$ interactions, with several short inter-atomic distances (presented by blue dotted lines in Fig. $2 \mathrm{~b}$ and $3 \mathrm{~b}$ ) ranging from $3.309(4)$ to $3.570(3) \AA$ for 2 and from 3.461(4) to 3.595(4) $\AA$ for 1. Moreover, it can be noted that the formation of $\mathrm{F} \cdots \mathrm{F}$ interactions, presented by green dotted lines, must enhance the stacking mode. The distances $d_{\mathrm{F} \cdots \mathrm{F}}$ ranging from $2.829(3) \AA$ to $2.889(3) \AA$ for 2 are shorter than for 1 with distances ranging from 2.920(2) Å to 3.182(2) Å, indicating a more strengthened stacking mode.

In the $b c$ plane the molecules are in contact via hydrogen bonds (orange dotted lines) and F ..F interactions (green dotted lines) as shown in Fig. 2c and 3c.

The main difference between the structures of compounds 1 and 2 lies in the lateral contacts between the columns of stacking of the molecules. For compound 2, several F $\cdots \mathrm{F}$ contacts with distances inferior to $3.0 \AA$, as shown by green dotted lines in Fig. 3d, stabilize the structure. Thus for compound 2 a packing mode in the three directions is observed without insertion of solvent leading to crystals presenting high stability at room temperature. By contrast for compound $\mathbf{1}$, the columns of molecules do not present any F. . F interaction. The shortest distances between the fluorine atoms are about $5 \AA$ giving spaces that allow the insertion of dichloromethane molecules between the columns. The molecules of solvent stabilize the structure of $\mathbf{1}$ by $\mathrm{Cl} \cdots \mathrm{F}$ interactions (purple dotted lines in Fig. 2d). Crystals of $\mathbf{1}$ are slowly disaggregated at room temperature for obtaining a powder. The analysis of the powder by thin layer chromatography and ${ }^{1} \mathrm{H}$ NMR always shows the

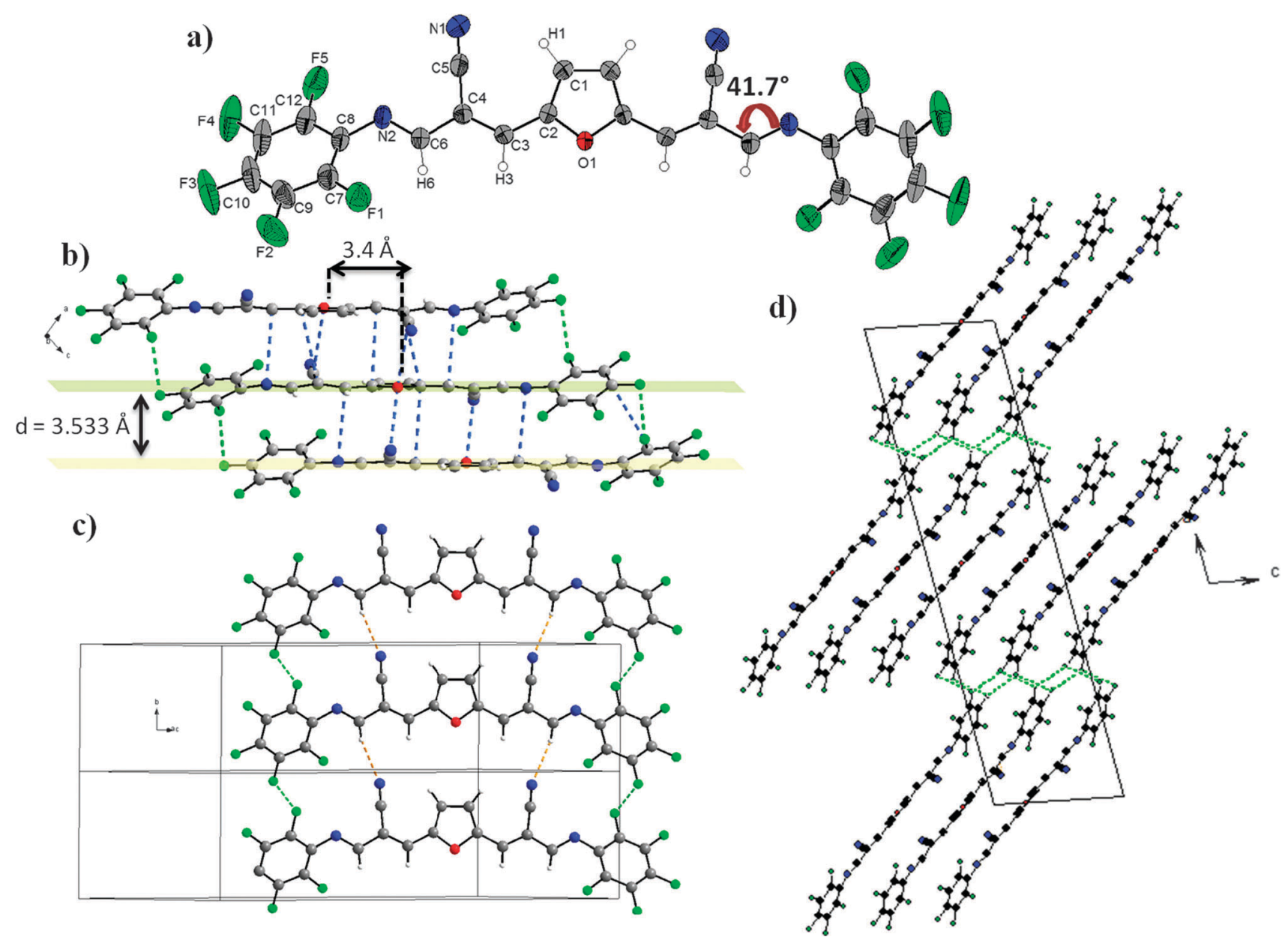

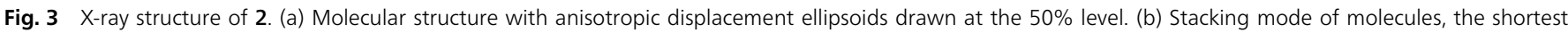

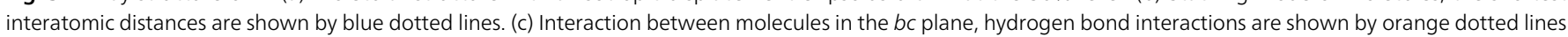

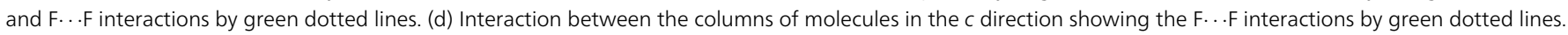




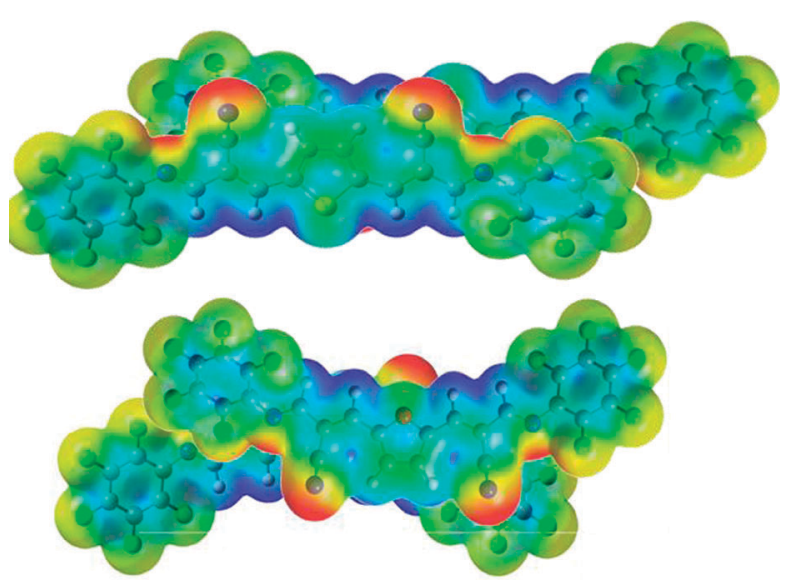

Fig. 4 ESP of compounds 1 and 2 and schematic representation of the superposition of two molecules of $\mathbf{1}$ (top) or $\mathbf{2}$ (bottom).

presence of compound $\mathbf{1}$, thus suggesting that the disaggregation of the crystal is due to the evaporation of the solvent at room temperature.

For a better understanding of the arrangement observed in the two X-ray structures, we have investigated the electrostatic surface potential (ESP) of the two compounds (Fig. 4). ${ }^{21}$ For both compounds the more negative potential regions (in red) are mainly located on the nitrogen atoms of the cyano groups and also on the nitrogen atoms of the imine bonds. The more positive potentials (in blue) are located on the hydrogen bonds both the imine and ethylenic bonds. The fluorine atoms present little negative potentials while the internal parts of the pentaflurobenzene have a little positive character. The interaction between the positive and negative regions is optimized by the overlapping of the molecules with the cyano groups presenting an opposite direction. Nevertheless several relative positions between the molecules are possible. As observed for compound 2, a cyano group overlaps the furan cycle in addition to the superposition of imine and ethylenic bonds. The $\pi$-stacking of this arrangement is strengthened by electrostatic interactions involving the cyano and furan units. For compound $\mathbf{1}$ a cyano group is superposed to an ethylenic bond while the second cyano is close to a perfluorophenyl ring. The slip-stacking of the two molecules thus mainly implicates $\pi-\pi$ interactions strengthened by smaller electrostatic character.

\section{Conclusion}

In conclusion, we have synthesized new examples of conjugated systems associating the cyano and the imino-perfluorophenyl units as withdrawing groups with furan or thiophene rings. The nature of the central heterocycle does not present any influence on the electronic properties of the conjugated materials. The comparison of the crystal structures of the two compounds evidences the subtle role of the central heteroatom for stabilizing the crystals. The two structures, which present a similar arrangement by showing a $\pi$-stacking of the molecules, differ by the halogen-halogen interactions existing between the columns of stacked molecules. The furan derivative with a more compact packing mode due to both $\pi-\pi$ and electrostatic interactions presents many $\mathrm{F} \cdots \mathrm{F}$ interactions which stabilize the structure. By contrast the structure of the thiophene derivative presents a larger shift of the molecules in the $\pi$-stacking and the structure is stabilized only in the presence of molecules of dichloromethane which develop $\mathrm{Cl} \cdots \mathrm{F}$ interactions between the columns. Although the solid phases of the films obtained by vacuum or by spin coating differ in the crystalline phases studied here, the strong intermolecular interactions observed in the crystals suggest that the compounds can present a packing mode adapted for their use as semi-conducting materials.

\section{Experimental section}

General information: NMR spectra were recorded on a Bruker Avance $300\left({ }^{1} \mathrm{H}\right.$ and $\left.{ }^{19} \mathrm{~F}: 300.1 \mathrm{MHz},{ }^{13} \mathrm{C}: 75.7 \mathrm{MHz}, T=300 \mathrm{~K}\right)$. The spectra were referenced against the internal NMR-solvent standard. Chemical shifts were expressed in parts per million (ppm) and were reported as s (singlet), dd (doublet doublet), $\mathrm{tt}$ (triplet triplet), and coupling constants $J$ were given in Hz. Mass spectra were recorded under MALDI-TOF mode on a MALDITOF-MS BIFLEX III Bruker Daltonics spectrometer. IR Spectra were performed on a Bruker VERETEX 70. UV-visible optical data were recorded on a Perkin-Elmer lambda 19 spectrophotometer. HPLC solvents were used for the measurements. Electrochemical experiments were performed with a Biologic SP150 potentiostat in a standard three-electrode cell using platinum electrodes and a saturated calomel reference electrode (SCE).

2,5-Dicarbaldehyde thiophene 3, 3,3-diethoxypropanenitrile 5 and pentafluorophenylaniline 8 were obtained commercially and used as received. 2,5-Dicarbaldehyde furan 4 was prepared by oxidation of HMF obtained by dehydration of D-glucose. ${ }^{32}$

\section{Synthetic procedure}

3,3'-(Thiophen-2,5-diyl)bis(2-formylacrylonitrile) (6). To a solution of $\mathrm{FeCl}_{3} \cdot 6 \mathrm{H}_{2} \mathrm{O}(17.75 \mathrm{mmol}, 25 \mathrm{~mol} \%)$ in ethanol $(2.0 \mathrm{~mL})$ were added thiophen-2,5-dicarbaldehyde $(0.100 \mathrm{~g}$, $71 \mathrm{mmol}$ ), 3,3-diethoxypropanenitrile ( 4 eq., $4.27 \mathrm{~mL}, 284 \mathrm{mmol}$ ) and acetic acid $(10 \mathrm{~mL})$, the mixture was stirred at $90{ }^{\circ} \mathrm{C}$ for $8 \mathrm{~h}$. Water was added to the mixture and the aqueous phase was extracted with dichloromethane. The combined organic phases were dried over $\mathrm{MgSO}_{4}$, evaporated under vacuum and the product was precipitated in $10 \mathrm{~mL}$ of dichloromethane. After filtration, the solid was recovered, washed with ethanol $(10 \mathrm{~mL})$ and dried under vacuum to give 6 as a brown solid (30\% yield).

Mp: $135{ }^{\circ} \mathrm{C} .{ }^{1} \mathrm{H}$ NMR (acetone- $\left.d_{6}\right): 9.72(\mathrm{~s}, 2 \mathrm{H}), 8.71(\mathrm{~s}, 2 \mathrm{H})$, $8.24(\mathrm{~s}, 2 \mathrm{H}) \mathrm{ppm}$. Mass (MALDI-TOF): $\mathrm{C}_{12} \mathrm{H}_{6} \mathrm{~N}_{2} \mathrm{O}_{2} \mathrm{~S}$, calcd 242.25 $\left(\mathrm{M}^{+}+\mathrm{H}\right)$, found 242.4. IR: 2220, $3092 \mathrm{~cm}^{-1}$.

3,3'-(Furan-2,5-diyl)bis(2-formylacrylonitrile) (7). To a solution of $\mathrm{FeCl}_{3} \cdot 6 \mathrm{H}_{2} \mathrm{O}(0.5 \mathrm{mmol}, 25 \mathrm{~mol} \%)$ in ethanol $(1.0 \mathrm{~mL})$ were added furan-2,5-dicarbaldehyde ( $0.250 \mathrm{~g}, 2 \mathrm{mmol}), 3,3$-diethoxypropanenitrile (4 eq., $1.14 \mathrm{~mL}, 8 \mathrm{mmol}$ ) and acetic acid $(5 \mathrm{~mL})$. The mixture was stirred at $90{ }^{\circ} \mathrm{C}$ for $8 \mathrm{~h}$. Water was added to the mixture and the aqueous phase was extracted with dichloromethane. The combined organic phases were dried over $\mathrm{MgSO}_{4}$, 
Table 2 Data collection parameters for crystals 1 and 2

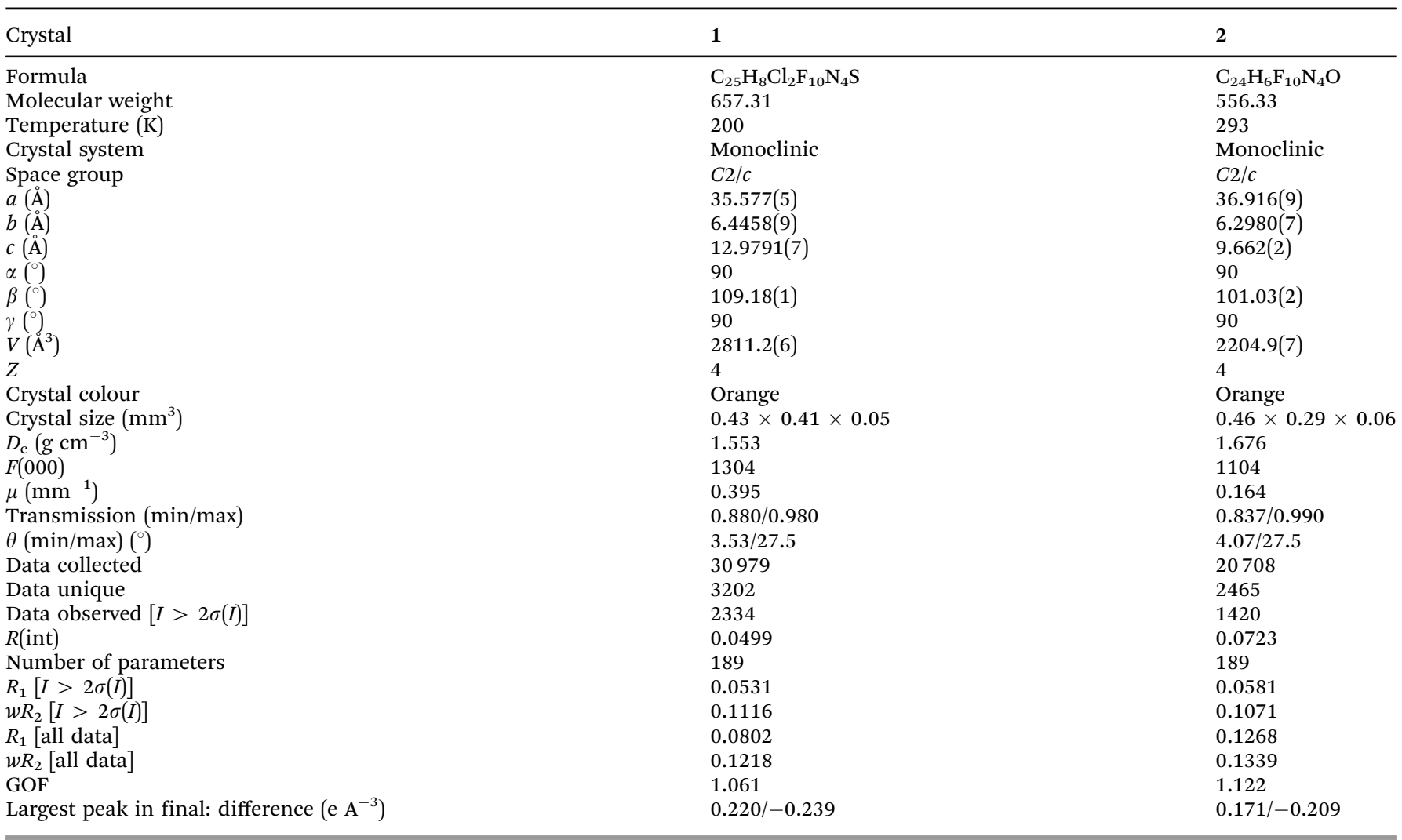

evaporated under vacuum, and the product was precipitated in $10 \mathrm{~mL}$ of dichloromethane. After filtration, the solid was recovered, washed with ethanol $(10 \mathrm{~mL})$ and dried under vacuum to give 7 as a brown solid (28\% yield).

Mp: $155{ }^{\circ} \mathrm{C} .{ }^{1} \mathrm{H}$ NMR (DMSO- $\left.d_{6}\right): 9.65$ (s, 2H), 8.43 (s, 2H), $7.82(\mathrm{~s}, 2 \mathrm{H})$ ppm. Mass (MALDI-TOF): $\mathrm{C}_{12} \mathrm{H}_{6} \mathrm{~N}_{2} \mathrm{O}_{3}$, calcd 226.04 $\left(\mathrm{M}^{+}+\mathrm{H}\right)$, found 226.3. IR: $2227,3036 \mathrm{~cm}^{-1}$.

$\left(2 Z, 2^{\prime} Z\right)-3,3^{\prime}$-(Thiophen-2,5-diyl)bis(2-((E)-(perfluorophenylimino)methyl)acrylonitrile) (1). 2,3,4,5,6-Pentafluorophenylaniline 8 (0.120 g, 4 eq., $66.0 \mathrm{mmol})$ and $\mathrm{P}_{2} \mathrm{O}_{5}(10 \% \mathrm{~mol})$ were successively added to a solution of $6(0.04 \mathrm{~g}, 16.5 \mathrm{mmol})$ in dichloromethane $(3 \mathrm{~mL})$ at room temperature and the mixture was stirred overnight. Then, water was added to the mixture and the aqueous phase was extracted with dichloromethane. The combined organic phases were dried over $\mathrm{MgSO}_{4}$, evaporated under vacuum and purified by column chromatography with dichloromethane as an eluent to give $\mathbf{1}$ as an orange solid (35\% yield).

Mp: $161{ }^{\circ} \mathrm{C} .{ }^{1} \mathrm{H}$ NMR (acetone- $\left.d_{6}\right): 8.76(\mathrm{~s}, 2 \mathrm{H}), 8.51(\mathrm{~s}, 2 \mathrm{H})$, $8.17(\mathrm{~s}, 2 \mathrm{H}) \mathrm{ppm} .{ }^{19} \mathrm{~F}$ NMR (acetone- $\left.d_{6}\right):-156.4(\mathrm{dd}, J=7 \mathrm{~Hz}, J=$ $21 \mathrm{~Hz}),-164.1(\mathrm{t}, J=21 \mathrm{~Hz}),-167.9(\mathrm{td}, J=7 \mathrm{~Hz}, J=21 \mathrm{~Hz}) \mathrm{ppm}$. ${ }^{13} \mathrm{C}$ (acetone- $d_{6}$ ): 166.5, 146.5, 143.2, 136.8, 130.4, $111.2 \mathrm{ppm}$. Mass (MALDI-TOF): $\mathrm{C}_{24} \mathrm{H}_{6} \mathrm{~F}_{10} \mathrm{~N}_{4} \mathrm{~S}$, calcd $572.02\left(\mathrm{M}^{+}+\mathrm{H}\right)$, found 573.6. IR: $1650,2220 \mathrm{~cm}^{-1}$.

$\left(2 Z, 2^{\prime} Z\right)-3,3^{\prime}$-(Furan-2,5-diyl)bis(2-((E)-(perfluorophenylimino)methyl)acrylonitrile)(2). 2,3,4,5,6-Pentafluorophenylaniline 8 (0.160 g, 4 eq., $88.4 \mathrm{mmol})$ and $\mathrm{P}_{2} \mathrm{O}_{5}(10 \% \mathrm{~mol})$ were successively added to a solution of $7(0.05 \mathrm{~g}, 22.1 \mathrm{mmol})$ in dichloromethane $(3 \mathrm{~mL})$ at room temperature and the mixture was stirred overnight. Then, water was added to the mixture and the aqueous phase was extracted with dichloromethane. The combined organic phases were dried over $\mathrm{MgSO}_{4}$, evaporated under vacuum and purified by column chromatography with dichloromethane as an eluent to give $\mathbf{2}$ as an orange solid (30\% yield).

Mp: $200{ }^{\circ} \mathrm{C} .{ }^{1} \mathrm{H}$ NMR (acetone- $d_{6}$ ): 8.79 (s, 2H), 8.15 (s, 2H), $7.83(\mathrm{~s}, 2 \mathrm{H}) \mathrm{ppm} .{ }^{19} \mathrm{~F}$ NMR (acetone- $\left.d_{6}\right):-156.3(\mathrm{dd}, J=6 \mathrm{~Hz}, J=$ $21 \mathrm{~Hz}),-164.0(\mathrm{t}, J=21 \mathrm{~Hz}),-167.9(\mathrm{td}, J=6 \mathrm{~Hz}$ and $21 \mathrm{~Hz})$ ppm. ${ }^{13} \mathrm{C}$ (acetone- $d_{6}$ ): $166.4,152.8,139.1,122.5,113.7,111.3$ ppm. Mass (MALDI-TOF): $\mathrm{C}_{24} \mathrm{H}_{6} \mathrm{~F}_{10} \mathrm{~N}_{4} \mathrm{O}$, calcd $556.04\left(\mathrm{M}^{+}+\mathrm{H}\right)$, found 557.5. IR: $1640,2225 \mathrm{~cm}^{-1}$.

\section{Crystallography}

X-ray single-crystal diffraction data were collected at $200 \mathrm{~K}$ for $\mathbf{1}$ and $293 \mathrm{~K}$ for 2 on a BRUKER KappaCCD diffractometer, equipped with a graphite monochromator utilizing $\mathrm{MoK} \alpha$ radiation $(\lambda=0.71073 \AA)$. The structures were solved by direct methods using SHELXS $97^{34}$ for 1 and SIR $2004^{35}$ for 2 and both were refined on $F^{2}$ by full-matrix least-squares method, using the SHELXL97 program. ${ }^{34}$ All non-hydrogen atoms were refined anisotropically and absorption was corrected by the SADABS program. The details of the data collection are gathered in Table 2 .

The $\mathrm{H}$ atoms were found by Fourier difference synthesis. During the structure refinement of compound $\mathbf{1}$, a region of electron density was identified as a highly disordered molecule 
of dichloromethane. This solvent cannot be correctly modeled but in the final structure model, the contribution of the electron density from the dichloromethane molecule has been removed from the intensity data using the program SQUEEZE ${ }^{36}$ in PLATON. ${ }^{37}$ Omission of the solvent molecule leaves 2 voids per unit cell and each hole of $338 \mathrm{~A}^{3}$ contains about 77 e which is consistent with the electron count of 2 molecules of dichloromethane per cavity (84 e). The assumed solvent composition (four dichloromethane molecules per unit cell) was included in the calculation of the empirical formula, formula weight, density, linear absorption coefficient and $F(000)$.

\section{Notes and references}

1 A. C. Arias, J. D. MacKenzie, I. McCulloch, J. Rivnay and A. Salleo, Chem. Rev., 2010, 110, 3.

2 A. Pron, P. Gawrys, M. Zagorska, D. Djurado and R. Demadrille, Chem. Soc. Rev., 2010, 39, 2577.

3 W. L. Leong, N. Mathews, B. Tan, S. Vaidyanathan, F. Dotz and S. Mhaisalkar, J. Mater. Chem., 2011, 21, 5203.

4 A. Mishra and P. Bäuerle, Angew. Chem., Int. Ed., 2012, 51, 2020.

5 B. Walker, C. Kim and T.-Q. Nguyen, Chem. Mater., 2011, 23, 470 .

6 M. Mas-Torrent and C. Rovira, Chem. Soc. Rev., 2008, 37, 827.

7 J. Roncali, Chem. Rev., 1997, 97, 173.

8 J. Roncali, Macromol. Rapid Commun., 2007, 28, 1761.

9 G. Barbarella, M. Melucci and G. Sotgiu, Adv. Mater., 2005, 17, 1581.

10 G. R. Desiraju, Angew. Chem., Int. Ed., 2007, 46, 8342.

11 C. B. Aakeroy, N. R. Champness and C. Janiak, CrystEngComm, 2010, 12, 22.

12 D. Fichou, J. Mater. Chem., 2000, 10, 571.

13 M. Mas-Torrent and C. Rovira, Chem. Rev., 2011, 111, 4833.

14 A. Facchetti, M. H. Yoon, C. L. Stern, H. E. Katz and T. J. Marks, Angew. Chem., Int. Ed., 2003, 42, 3900.

15 M.-H. Yoon, A. Facchetti, C. E. Stern and T. J. Marks, J. Am. Chem. Soc., 2006, 128, 5792.

16 C. Videlot-Ackermann, H. Brisset, J. Zhang, J. Ackermann, S. Néon, F. Fages, P. Marsal, T. Tanisawa and N. Yoshimoto, J. Phys. Chem. C, 2009, 113, 1567.

17 Y. Didane, R. Ponce Ortiz, J. Zhang, K. Aosawa, T. Tanisawa, H. Aboubakr, F. Fages, J. Ackermann, N. Yoshimoto, H. Brisset and C. Videlot-Ackermann, Tetrahedron, 2012, 68, 4664.

18 F. Babudri, G. M. Farinola, F. Naso and R. Ragni, Chem. Commun., 2007, 1003.
19 S. Clement, F. Meyer, J. De Winter, O. Coulembier, C. M. L. Vande Velde, M. Zeller, P. Gerbaux, J.-Y. Balandier, S. Sergeyev, R. Lazzaroni, Y. Geerts and P. Dubois, J. Org. Chem., 2010, 75, 1561.

20 D. J. Crouch, P. J. Skabara, M. Heeney, I. McCulloch, S. J. Coles and M. B. Hursthouse, Chem. Commun., 2005, 1465.

21 D. J. Crouch, P. J. Skabara, J. E. Lohr, J. J. W. McDouall, M. Heeney, I. McCulloch, D. Sparrowe, M. Shkunov, S. J. Coles, P. N. Horton and M. B. Hursthouse, Chem. Mater., 2005, 17, 6567.

22 X. Cai, M. W. Burand, C. R. Newman, D. A. da Silva Filho, T. M. Pappenfus, M. M. Bader, J.-L. Brédas, K. R. Mann and C. D. Frisbie, J. Phys. Chem. B, 2006, 110, 14590.

23 J.-Y. Balandier, F. Quist, C. Amato, S. Bouzakraoui, J. Cornil, S. Sergeyev and Y. Geerts, Tetrahedron, 2010, 66, 9560.

24 R. Li, W. Hu, Y. Liu and D. Zhu, Acc. Chem. Res., 2010, 43, 529.

25 M. M. Bader, R. Custelcean and M. D. Ward, Chem. Mater., 2003, 15, 616.

26 M. M. Bader, P.-T. T. Pham and E. H. Elandaloussi, Cryst. Growth Des., 2010, 10, 5027.

27 Y. Miyata, M. Terayama, T. Minari, T. Nishinaga, T. Nemoto, S. Isoda and K. Komatsu, Chem.-Asian J., 2007, 2, 1492.

28 O. Gidron, A. Dadvand, Y. Sheynin, M. Bendikov and D. F. Perepichka, Chem. Commun., 2011, 47, 1976.

29 C. H. Woo, P. M. Beaujuge, T. W. Holcombe, O. P. Lee and J. M. J. Fréchet, J. Am. Chem. Soc., 2010, 132, 15547.

30 J. C. Bijleveld, B. P. Karsten, S. G. J. Mathijssen, M. M. Wienk, D. M. de Leeuw and R. A. J. Janssen, J. Mater. Chem., 2011, 21, 1600.

31 J. T. Lin, P.-C. Chen, Y.-S. Yen, Y.-C. Hsu, H.-H. Chou and M.-C. P. Yeh, Org. Lett., 2009, 11, 97.

32 C. Mallet, M. Allain, P. Leriche and P. Frère, CrystEngComm, 2011, 13, 5833.

33 S. Maeda, N. Horikawa, Y. Obora and Y. Ishii, J. Org. Chem., 2009, 74, 9558.

34 G. M. Sheldrick, [Includes SHELXS97, SHELXL97] Programs for Crystal Structure Analysis, Göttingen, Germany, 1998.

35 M. C. Burla, R. Caliandro, M. Camailli, B. Carrozzini, G. L. Cascarano, L. De Caro, C. Giacovazzo, G. Polidori and R. Spagna, J. Appl. Crystallogr., 2005, 38, 381.

36 P. van der Sluis and A. L. Spek, Acta Crystallogr., Sect. A: Found. Crystallogr., 1990, 46, 194.

37 A. L. Spek, PLATON, A Multipurpose Crystallographic Tool, Utrecht University, The Netherlands, 2005. 